\title{
О ПРОБЛЕМАХ ОЦЕНКИ ИНВЕСТИЦИЙ В ПРОЕКТЫ, НАПРАВЛЕННЫЕ НА ЦИФРОВИЗАЦИЮ ПРОИЗВОДСТВА
}

\author{
(C) 2019 Чудаева Александра Александровна \\ кандидат экономических наук, доцент, \\ кафедра экономики, организации и стратегии развития предприятия \\ Самарский государственный экономический университет, Россия, Самара
}

В статье рассмотрены проблемы, возникающие в процессе оценки инвестиций в проекты, направленные на цифровизацию производства, и предложения по их преодолению, заключающиеся в тщательной проработке исходной информации, рассмотрению возможностей применения инструментов господдержки таких проектов, включению рисков в расчеты эффективности.

Ключевые слова: цифровизация производства, инвестиционный проект, оценка экономической эффективности, риск, технико-экономическое обоснование.

Развитие цифровых технологий порождает неконтролируемые изменения в обществе и бизнесе. Цифровизация производственных предприятий требует огромных инвестиций. И здесь возникают вопросы о том, располагают ли российские производственные предприятия средствами, которые можно было бы инвестировать в цифровизацию производства, способны ли они привлечь кредиты для финансирования такого рода проектов, готовы ли ждать когда наступит срок окупаемости.

Обычно в бизнесе воплощаются в жизнь проекты, которые на этапе их оценки признаны эффективными. Определить экономическую эффективность проекта - это соотнести результаты, которые он принесет предприятию, с затратами на его реализацию с учетом интересов инвесторов, вкладывающих средства в этот проект.

Оценка эффективности инвестиционных проектов (инвестиционными являются проекты, для реализации которых необходимы инвестиции) должна осуществляться в соответствии с «Методическими рекомендациями по оценке эффективности инвестиционных проектов» (утв. Минэкономики РФ, Минфином РФ, Госстроем РФ 21.06.1999 N BК 477) [5], применение которых предполагает формирование денежных потоков как основы для определения показателей экономической эффективности.

Определение денежных потоков проектов, направленных на внедрение цифровых технологий в деятельность предприятий, предполагает наличие необходимой для этого информации, которая включает в себя сведения обо всех по- следствиях процесса цифровизации в денежном выражении.

И если снижение трансакционных издержек вследствие цифровизации не оспоримо, то однозначно трактовать результаты инкорпорации цифровых технологий в производство затруднительно. Причина этому - большое число факторов, оказывающих влияние на деятельность производственного предприятия, и невозможность достоверно спрогнозировать влияние каждого фактора в отдельности и в совокупности с другими на результаты системы (предприятия).

Неполнота и неточность информации, используемой в процессе оценки экономической эффективности инвестиционного проекта, порождает риски, которые инвестор может быть не готовым принять. И, как следствие, проекты, связанные с внедрением цифровых технологий в производство, будут менее привлекательными для реализации в сравнении с проектами, направленными на использование на предприятиях программ и технологий, позволяющих решать экономические, логистические, организационные, расчетные, поисковые задачи. Данные Федеральной службы государственной статистики (Росстат) отражают описанную тенденцию.

Росстат фиксирует информацию об удельном весе организаций, использовавших специальные программные средства [11]. Согласно данным Росстата за последние десять лет, доля предприятий, использовавших специальные программные средства для управления автоматизированным производством и/или отдельными техническими средствами и технологическими процессами, невелика. В период с 2011 г. по 
2017 г. наблюдается снижение этого значения. Доля предприятий, использовавших CRM, ERP, SCM - системы, также незначительна. Но динамика изменения по данному критерию положительная. Однако судить о том, какая часть приходится на ERP-системы, включающие в себя трансформацию производственных процессов, по данным Росстата не представляется возможным.

Невысокую заинтересованность предприятий в цифровизации производства подтверждают и данные совместного исследования компании «Цифра» и Министерства промышленности и торговли РФ [9], согласно которому затраты пятидесяти пяти процентов промышленных предприятий Российской Федерации на цифровизацию и развитие информационной инфраструктуры менее одного процента от их бюджета. В данном исследовании отмечается, что только у шести процентов предприятий затраты составляют более пяти процентов бюджета.

Таким образом, цифровизация производственных предприятий в РФ идёт медленными темпами, лишь малая доля отечественных компаний может похвастаться производством, полностью основанным на цифровых технологиях (ПАО «КамАЗ», концерн «Калашников», «РусАл», «Петрозаводскмаш» и другие [1]). Сложившаяся ситуация обусловлена сложностью производственных предприятий из-за наличия стадии производства, которая в зависимости от специфики деятельности компании, может быть очень продолжительной во времени.

Очевидно, что во всех отраслях ситуации абсолютно разные. Отрасли, демонстрирующие рост, имеют прибыль, которую можно инвестировать в развитие производства и за счет генерируемой нормы прибыли могут рассчитывать на приток капитала в свои проекты извне. Отрасли, которые не показывают рост и имеют небольшую норму прибыли, не способны собственными силами реализовывать проекты, связанные с цифровизацией производства. Следовательно, нужно привлекать кредитные средства, стоимость пользования которыми доступна далеко не всем предприятиям, в том числе из-за продолжительного срока окупаемости проектов, связанных с созданием и развитием производственных предприятий. И здесь необходимо отметить, что государство помогает решать предприятиям проблему нехватки средств на реализацию проектов цифровизации произ- водства с помощью различных инструментов.

Предоставление субсидий - один из способов решения вышеописанной проблемы. Так, Министерством промышленности и торговли РФ в 2019 году был объявлен конкурсный отбор на право получения субсидий из федерального бюджета на разработку индустриальных цифровых платформ (правила предоставления субсидий вступили в силу 30 апреля 2019 г. (постановление Правительства Российской Федерации № 529 [7])). По итогам первого этапа этого конкурса был отобран 61 проект [6]. И это уже второй запущенный отбор проектов в рамках работы инструментов федерального проекта «Цифровые технологии». Согласно данным АНО «Цифровая экономика», непосредственно на разработку индустриальных цифровых платформ в 2019 году планируется направить два миллиарда рублей субсидий из федерального бюджета [6].

Второй способ - предоставление займов на условиях софинансирования. В РФ создан Фонд развития промышленности [12], который дает займы на воплощение в жизнь проектов, направленных внедрение цифровых и технологических решений, призванных оптимизировать производственные процессы на предприятии.

Как для получения субсидий, так и для софинансирования от фонда развития промышленности следует провести технико-экономическое обоснование (ТЭО) инвестиционного проекта, направленного на цифровизацию производства. В рамках ТЭО особое внимание следует уделить рискам такого проекта.

Как было сказано выше, проекты, связанные с цифровизацией производства, из-за неполноты и неточности информации о последствиях внедрения цифровых технологий в производственную деятельность предприятия, могут привести к возникновению рисковых ситуаций, что должно быть учтено в расчетах эффективности.

Известны три направления включения рисков в расчеты эффективности инвестиционных проектов [13]. В рамках первого направления в процессе формирования исходной информации по проекту, направленному на цифровизацию производства, должны быть предусмотрены затраты на приобретение резервных производственных мощностей (необходимость в них зависит от отрасли), расходы, связанные с ремонтом и техническим обслуживанием (ТО) внедряемых технологий, и периодичность проведения различных видов ремонтов и ТО. Но здесь 
могут возникнуть трудности с обоснованием как самой необходимости учета такого рода затрат, так и величин, и периодичности их возникновения в оттоках проекта. Цифровые технологии это инновации, поведение которых всегда носит вероятностный характер.

Инновационность сказывается и на норме доходности, на которую ориентируется инвестор. Чем выше риск, тем выше требования инвестора к уровню доходности такого проекта. Норма дохода (второе направление включения рисков в расчеты эффективности) учитывается в процессе технико-экономического обоснования инвестиционного проекта в расчете ставки дисконтирования, влияющей на значение чистой приведенной стоимости (NPV) проекта. Чем выше требования инвестора, тем ниже чистая приведенная стоимость, тем сложнее внутренней норме рентабельности проекта соответствовать норме дохода. А это значит, что из-за включаемых в норму дохода рисков, величина которых зачастую является в инновационных проектах предметом экспертной оценки, могут быть признаны неэффективными проекты, направленные на цифровизацию производства.

Третьим направлением включения рисков в расчеты эффективности является проведение анализа чувствительности, в рамках которого следует оценить влияние внешних факторов на эффективность инвестиционного проекта.

Кроме уже затронутых вопросов, касающихся оценки инвестиций в проекты, направленные на цифровизацию производства, следует обратить внимание еще на один аспект - трудовые ресурсы предприятия. В процессе проведения ТЭО затраты на оплату труда персонала является оттоком денежных средств из проекта. Следовательно, сокращение затрат на персонал - одно из направлений повышения эффективности инвестиционных проектов. И на первый взгляд здесь нет противоречия, потому что общепринятым считается утверждение, что цифровизация производства приведет к тотальной роботизации и автоматизации и высвобождению людей, работающих на производстве [3]. Будет ли ситуация таковой в каждом конкретном случае? Для ответа на этот вопрос необходимо проводить расчеты, позволяющие оценить количество персонала, требуемый уровень его квалификации и средний уровень заработной платы такими специалистами на рынке труда.

Почему возникают сомнения в однозначности подхода, утверждающего, что цифровизация - это снижение затрат на персонал. Во-первых, цифровизация предполагает использование высококвалифицированного труда (программисты, специалисты по обслуживанию и ремонту оборудования с программным обеспечением и т.п.). Во-вторых, предприятия будут внедрять цифровые технологии тогда, когда более рентабельно будет купить технологию, а не оплатить труд человека. В настоящее время уровень заработных плат работающих россиян таков, что совсем не очевидным является факт выгодности замены его труда на робота. Согласно данным Росстата, с небольшим перерывом доходы населения падают с 2014 года [10].

Если цифровизация будет способствовать тому, что население будет лишаться работы, то бизнесу и государству следует задуматься, нужна ли цифровизация такой ценой. Рост безработицы на фоне закредитованности населения может привести к крайне неблагоприятным социальным последствиям. Однако более вероятным видится сценарий, согласно которому произойдут изменения в структуре занятости населения, трансформируется рынок труда и подходы к обучению. Согласно докладу WEF, в ближайшем будущем роботы уничтожат в мире больше семидесяти пяти миллионов рабочих мест и создадут сто тридцать три миллиона новых [2].

Таким образом, определение экономической эффективности вложения инвестиций в проекты, направленные на цифровизацию производства, сопряжено с целым комплексом проблем поиска и обработки информации, неполнота и неточность которой порождает риски. Их много, и предметом оценки должны стать последствия от наступления каждого из возможных рисковых обстоятельств, т.к. стоимость их проявления может стать несоизмеримо большой в сравнении с теми положительными эффектами, на которые направлен проект.

\section{Библиографический список}

1. Бельзер М. Цифровизация промышленности: модный тренд или необходимое условие для сохранения конкурентоспособности? - Режим доступа: https://promdevelop.ru/tsifrovizatsiya-promyshlennosti-modnyjtrend-ili-neobhodimoe-uslovie-dlya-sohraneniya-konkurentosposobnosti/ (10.10.2019) 
2. Заутер А. Как цифровая трансформация изменит рынок труда в России.- Режим доступа: https://www. forbes.ru/karera-i-svoy-biznes/371537-kak-cifrovaya-transformaciya-izmenit-rynok-truda-v-rossii (14.11.2019).

3. Замена людей роботами: в каких сферам проходит активная замена и грозит ли нам это безработицей.Режим доступа: https://viafuture.ru/katalog-idej/zamena-lyudej-robotami (12.11.2019)

4. Инвестиции, итоги 2018 года: новые сюрпризы и новые надежды.- Бюллетень «Комментарии о Государстве и Бизнесе». № 199, 28 марта 2019.- С. 1-7.

5. Методические рекомендации по оценке эффективности инвестиционных проектов (утв. Минэкономики РФ, Минфином РФ, Госстроем РФ 21.06.1999 N ВК 477).- Режим доступа: http:/www.consultant.ru/ document/cons_doc_LAW_28224/b26b2e47bd38905e1b2e8e82c424a69d639de743/ (02.11.2019)

6. Минпромторг отобрал 61 проект по цифровым решениям для промышленности.- Режим доступа: https://ria.ru/20190905/1558328608.html (15.11.2019)

7. Постановление Правительства РФ от 30.04.2019 N529 (ред. от 26.09.2019) «Об утверждении Правил предоставления субсидий российским организациям на возмещение части затрат на разработку цифровых платформ и программных продуктов в целях создания и (или) развития производства высокотехнологичной промышленной продукции».- Режим доступа: http://www.consultant.ru/document/cons_doc_LAW_324050/ (15.11.2019)

8. Программа «Проекты развития». Фонд развития промышленности. - Режим доступа: http://frprf.ru/zaymy/ tsifrovizatsiya-promyshlennosti/ (11.11.2019)

9. Разумный Е. Минпромторг оценил готовность российских предприятий к цифровизации.- Режим доступа: https://www.rbc.ru/technology_and_media/03/07/2018/5b3a26a89a794785abc9f304 (11.11.2019)

10. Реальные доходы россиян продолжили падение. - Режим доступа: https://www.rbc.ru/economics/17/07/2019/5d2f07959a79477db606e26f (12.11.2019)

11. Удельный вес организаций, использовавших персональные компьютеры, по субъектам Российской Федерации) (в процентах от общего числа обследованных организаций соответствующего субъекта Российской Федерации) на 27.07.2018 г. Федеральная служба государственной статистики (Росстат). http://www.gks.ru/ free_doc/new_sit e/business/it/it7.xls (16.10.2019)

12. Фонд развития промышленности (ФГАУ «Российский фонд технологического развития»). Официальный сайт.- Режим доступа: https://frprf.ru/

13. Экономическая оценка инвестиций: Учебник для вузов. 5-е изд., переработанное и дополненное (+ обучающий курс).- СПб.: Питер, 2014. - 432 с.: ил. - (Серия «Учебник для вузов»).- С. 298. 